\title{
Life Skills Approach - An Interactive Nursing Approach
}

\author{
Mr. Ravindra H.N, \\ M.Sc (N),M.Phil. Principal, Sumandeep Nursing College, Vadodara, Gujarat.
}

\begin{abstract}
The life skills approach is an interactive, educational methodology that focuses on transmitting knowledge and aims at shaping attitudes and developing interpersonal skills. The main goal of the life skills approach is to enhance young people`'s ability to take responsibility for making healthier choices, resisting negative pressures, and avoiding risk behaviors. Teaching methods are youth-centered, gender-sensitive, interactive, and participatory. The most common teaching methods include working in groups, brainstorming, role-playing, storytelling, debating, and participating in discussions and audiovisual activities.
\end{abstract}

\section{Introduction:}

The life skills approach is an interactive, educational methodology that focuses on transmitting knowledge and aims at shaping attitudes and developing interpersonal skills. The main goal of the life skills approach is to enhance young people's ability to take responsibility for making healthier choices, resisting negative pressures, and avoiding risk behaviors. Teaching methods are youth-centered, gender-sensitive, interactive, and participatory. The most common teaching methods include working in groups, brainstorming, role-playing, storytelling, debating, and participating in discussions and audiovisual activities.

Research demonstrates that possessing life skills may be critical to young people's ability to positively adapt to and deal with the demands and challenges of life. Some programs effectively teach and promote life skills. This paper briefly reviews some of these programs and presents lessons learned from the life skills approach to HIV prevention education. These lessons are also applicable to a wide range of sexual and reproductive health programs for youth.

Over the past twenty years, "life skills" have become part of the vocabulary in alcohol education and the prevention of alcohol misuse. The term refers to programs targeted primarily at young people and based on the need to promote healthy lifestyles through health education. Life skills education emerged from a growing concern about certain health problems with particular impact on young people, including HIV/AIDS, sexual behavior, drugs, peer influence, and youth suicide. The emphasis of this approach is on basic personal and social skills, attitudes, and knowledge helpful in making positive decisions and lifestyle choices.

Life skills are essentially those abilities that help promote mental well-being and competence in young people as they face the realities of life. Most development professionals agree that life skills are generally applied in the context of health and social events.

\section{Definition:}

WHO has defined life skills as, "the abilities for adaptive and positive behaviour that enable individuals to deal effectively with the demands and challenges of everyday life".

UNICEF defines life skills as "a behaviour change or behaviour development approach designed to address a balance of three areas: knowledge, attitude and skills".

\section{GOALS OF THE LIFESKILLS:}

* Counseling can include providing emotional support

* Managing specific problem situations better

* Managing problems

* Improving poor skills that sustain problems

\section{APPLICATIONS OF LIFESKILLS :}

Effective in educating youth about health-related issues such as:

* Prevention of drug use

* Sexual violence

* Teenage pregnancy

* HIV/AIDS prevention

* Suicide prevention

* Consumer education

* Environmental education 
* Peace education

* preventing school dropout

* Violence among young people.

* Social cultural Issue

Life skills counseling involves the processes of thinking, feeling, and acting that develop an attitude favoring positive change, knowledge revealing how to change, and skills in realizing desired changes. It focuses on the problems and the potential of people focusing on a person's strengths in the hope that change and selfdevelopment will eventually take place. In the context of life skills counseling the Behavior change process means consistently using skills to describe and analyze people's behavior with specific focus on thinking and talking about client's problems in terms of life skills strengths and deficits.

\section{Core Life Skill Strategies And Techniques:}

UNICEF, UNESCO and WHO list the ten core life skill strategies and techniques

The Ten core Life Skills as laid down by WHO are:

1. Self-awareness

2. Empathy

3. Critical thinking

4. Creative thinking

5. Decision making

6. Problem Solving

7. Effective communication

8. Interpersonal relationship

9. Coping with stress

10. Coping with emotion

1. Self-awarenes: includes recognition of 'self', our character, our strengths and weaknesses, desires and dislikes. Developing self-awareness can help us to recognize when we are stressed or feel under pressure. It is often a prerequisite to effective communication and interpersonal relations, as well as for developing empathy with others.

2. Empathy: - Empathy is the ability to imagine what life is like for another person. Empathy can help us to accept others, who may be very different from ourselves. This can improve social interactions, especially, in situations of ethnic or cultural diversity.

Empathy can also help to encourage nurturing behaviour towards people in need of care and assistance, or tolerance, as is the case with AIDS sufferers, or people with mental disorders, who may be stigmatized and ostracized by the very people they depend upon for support.

3. Critical thinking is an ability to analyze information and experiences in an objective manner. Critical thinking can contribute to health by helping us to recognize and assess the factors that influence attitudes and behaviour, such as values, peer pressure and the media.

4. Creative thinking: is a novel way of seeing or doing things that is characteristic of four components fluency (generating new ideas), flexibility (shifting perspective easily), originality (conceiving of something new), and elaboration (building on other ideas).

5. Decision making: helps us to deal constructively with decisions about our lives. This can have consequences for health. It can teach people how to actively make decisions about their actions in relation to healthy assessment of different options and, what effects these different decisions are likely to have.

6. Problem solving: helps us to deal constructively with problems in our lives. Significant problems that are left unresolved can cause mental stress and give rise to accompanying physical strain.

7. Interpersonal relationship skills: help us to relate in positive ways with the people we interact with. This may mean being able to make and keep friendly relationships, which can be of great importance to our mental and social well-being. It may mean keeping, good relations with family members, which are an important source of social support. It may also mean being able to end relationships constructively. 6

8. Effective communication: means that we are able to express ourselves, both verbally and non-verbally, in ways that are appropriate to our cultures and situations. 
This means being able to express opinions and desires, and also needs and fears. And it may mean being able to ask for advice and help in a time of need.

9. Coping with stress: means recognizing the sources of stress in our lives, recognizing how this affects us, and acting in ways that help us control our levels of stress, by changing our environment or lifestyle and learning how to relax.

10. Coping with emotions: means involving recognizing emotions within us and others, being aware of how emotions influence behaviour and being able to respond to emotions appropriately. Intense emotions like anger or sadness can have negative effects on our health if we do not respond appropriately.

\section{TECHNIQUES OF LIFE SKILLS EDUCATION:}

Lifes skill and involves all or some of the following techniques:

- Dynamic teaching \& Dynamic learning

- Working in small groups \& pairs

- Brainstorming

- Role-plays

- Experiential learning

- Games \& debates

- Home assignments, to further discuss and practice skills with family \& friends.

- Demonstration and guided practice

- Simulations

- Case studies

- Story telling

- Debates

\section{Steps In Lifeskills Application:}

Defining and Promoting Life Skills

- Defining the skills: What skills are most relevant to influencing a targeted

behaviour or condition. What will the student be able to do if the skill-building exercises are successful?

- Generating positive and negative examples of how the skills might be applied

- Encouraging verbal rehearsal and action

- Correcting misperceptions about what the skill is and how to do it.

Promoting Skills Acquisition and Performance

- Providing opportunities to observe Life skills being applied effectively

- Providing opportunities for practice with coaching and feedback.

- Evaluating performance.

- Providing feedback and recommendations for corrective action.

Fostering Skill Maintenance/Generalisation

- Providing opportunities

- Fostering self - evaluation and skill adjustment.

\section{SUMMARY:}

- "Life skills" is an approach to alcohol education that encourages the development of skills needed to make responsible and informed choices.

- The main objective of life skills education is to promote healthy lifestyles through health education.

- The approach has been integrated into curriculum development for schools and has also been implemented through other channels.

- Life skills approach includes elements that make it easy to adapt to different cultures and appropriate for implementation in both developing and developed countries.

- Due to the broad nature of the skills it develops, the effectiveness of this approach may not be easy to quantify.

\section{References:}


[1] UNICEF. Skills-Based Health Education to Prevent HIV/AIDS. New York: UNICEF, [2000?]. For more information, visit www.unicef.org/programme/lifeskills/mainmenu.html.

[2] Centre for Development \& Population Activities (CEDPA). Adolescent Girls in India Choose a Better Future: An Impact Assessment. Washington, DC: CEDPA, 2001.

[3] United Nations Joint Programme on HIV/AIDS (UNAIDS). UNAIDS Best Practices in School AIDS Education, the Zimbabwe Case Study. New York: UNAIDS, 2000. For more information on AIDS Action Programme for Schools, visit www.unicef.org/programme/lifeskills/focus/field.html.

[4] Philliber Research Associates. Preventing Teen Pregnancy and Academic Failure: Experimental Evaluation of a Developmentally Based Approach. Accord, NY: The Associates, 1997.

[5] Qualifications for a Life Skills Counselor | eHow.com http://www.ehow.com/about 5128375 qualifications-life-skillscounselor.html\#ixzz1WxR9aIsy. 